\title{
Collaborative Design Work in Technology Education
}

\author{
Kangas, Kaiju
}

Springer International Publishing

2018

Kangas , K \& Seitamaa-Hakkarainen , P 2018 , Collaborative Design Work in Technology

Education . in M J de Vries (ed.), Handbook of Technology Education . Springer

International Handbooks of Education, no. 1, Springer International Publishing , Cham , pp.

597-609 . https://doi.org/10.1007/978-3-319-38889-2_44-1

http://hdl.handle.net/10138/310144

https://doi.org/10.1007/978-3-319-38889-2_44-1

unspecified

acceptedVersion

Downloaded from Helda, University of Helsinki institutional repository.

This is an electronic reprint of the original article.

This reprint may differ from the original in pagination and typographic detail.

Please cite the original version. 


\title{
Collaborative Design Work in Technology Education
}

\author{
Kaiju Kangas \& Pirita Seitamaa-Hakkarainen
}

Department of Teacher Education, University of Helsinki, Finland kaiju.kangas@helsinki.fi

\begin{abstract}
This chapter examines how designing, particularly collaborative designing, could be promoted in technology education classrooms. A few pedagogical models, where the design process is approached through collaborative inquiry, are presented. One approach, Learning by Collaborative Design (LCD) is described in greater detail, because of its unique applicability to technology education. The approach focuses on object-oriented learning, i.e. learning activities organized around the systematic and deliberate pursuit of knowledge-creation by constructing design artifacts. The chapter introduces focal elements of the LCD model, such as authentic design tasks that balance openness and constraints, as well as promotion of mediated and embodied design practices, and discusses their implications for technology education. In conclusion, the linkage between design learning and the maker movement is examined, and directions for future research are proposed.
\end{abstract}

\section{Introduction}

In the contemporary world, design is all-pervasive, with the social, cultural, and environmental effects of design apparent either directly or through various media. Designed artifacts and solutions affect our lives and values, both from a personal and societal perspective. In a broad sense, design concerns the ways in which human beings modify their environments to better satisfy their needs and wants (e.g. de Vries, 2009; ITEA, 2007). In many cases, the design process is realized through working with various materials and technologies. Furthermore, the visual and technical knowledge of designing is essential; students learn how to generate design ideas, develop their ability to advance the ideas by drawing and using CAD tools (e.g. Kelley \& Sung, 2016), and learn to materialize their ideas with different tools, techniques, and materials (e.g. Welch, 1998). Consequently, the overall aim of design learning in general education (i.e. elementary and secondary school) can be seen as generating a basic understanding of how design and technology affect the world, and how we exist around design and technology (de Vries, 2009; ITEA, 2007). Thus it can be argued that, design is at the core of technology education, and 
neither design nor technology can be fully appreciated without an understanding of the other.

Both design and technology are still a newcomers in education; in most Western countries design and technology education has been developed only in the past two or three decades (de Vries, 2009). There is considerable variation between countries in how design is included in the curriculum and used in the classroom (e.g. Kelley \& Sung, 2016). In some countries (such as U.K.), design is included in technology education, in others, it is a cross-curricular subject, or integrated with other school subjects, such as science, art, home economics, or craft. Design can be a subject of investigation, a means of investigation, or both. It can be either compulsory or optional. Thus, design education lacks the identity and long tradition of a well-established subject, such as mathematics or science, and still needs a framework and a basic concept as a subject in education (Dahlin, Voll, \& Svorkmo, 2013).

This chapter examines how collaborative designing could be promoted within technology education. As with any other form of intelligence, design competence is not a given "talent" or "gift," but can be learned and developed. Learning through design (Harel, 1991) is based on a constructionist theory that regards learners as builders of their own knowledge (Kafai, 2006; Papert, 1991) and sees learning not only as the development of knowledge, but also as the cultivation of ways of thinking and acting. Collaborative designing refers to a process in which students actively communicate and work together in identifying design constraints, creating and sharing design ideas, deliberately making joint decisions and producing shared design objects, constructing and modifying their design solutions, as well as evaluating their outcomes through discourse (Hennessy \& Murphy, 1999). As the design process closely resembles inquiry process, this chapter, first, presents a few pedagogical models where the design process is approached with collaborative inquiry. Then, one model, the Learning by Collaborative Design -model, is described more thoroughly, as it is considered especially applicable to technology education. Focal elements of the model, design problems and constraints, as well as mediated and embodied design practices, are presented, and implications for technology education discussed. Finally, conclusions and future directions of designing within technology education will be considered.

\section{Approaching Design and Technology through Collaborative Inquiry}

Inquiry-based approaches to design and technology education have originally been developed in countries (such as the U.S.), where mainly technology, but also design, have been considered as part of STEM-education. These approaches purposefully 
use design and technology as a vehicle for constructing new science knowledge. Integrating design and technology with science is seen as a valuable process, allowing students to construct a deep understanding of scientific principles. An inquiry approach (e.g. Fox-Turnbull, this volume; Krajick \& Merritt, 2012) to the scientific process emphasizes, for example, asking questions, planning investigations, using resources to find information, analyzing data, communicating results, and recognizing and analyzing alternative explanations and predictions. Learning through design encourages students to engage in many of these practices.

Learning by Design ${ }^{\mathrm{TM}}$ (LBD) (Kolodner et al., 2003) and Design-Based Science (DBS) (Fortus et al., 2004) are programs in which a design challenge provides students a reason for learning science content; engaging in the challenge provides an authentic and meaningful context for using both science and design skills. In both LBD and DBS classrooms, the work is built on multiple iterative cycles of constructing, evaluating, and revising models, along with discussion of issues that arise while solving the design challenge. The main distinction between the programs is that in LBD all iterations focus on the same science concepts, but at increasing levels of complexity, whereas in DBS each iteration focuses on a different science concept. However, each cycle also returns to the concepts presented in former cycles in order to facilitate the development of a deep understanding of each of the studied concepts. LBD and DBS have much in common with other inquiry-based programs, which all share certain features: they (a) focus on authentic tasks for lengthy periods of time, (b) lead to the creation of artifacts, (c) encourage the use of alternative assessment methods, (d) make use of computer-based technology, (e) build upon collaboration, and (f) view the teacher as a facilitator and a learner along with the students.

The inquiry activities common to science classrooms can be used as a part of design and technology education (Krajick \& Merritt, 2012). However, designing also includes many features that cannot be reached through logical reasoning or other methods used in science. In order to support students and teachers in engaging in an inquiry-based approach to design within technology, two pedagogical models have been developed: Design-Oriented Pedagogy (DOP) (Liljeström et al., 2014; Vartiainen et al., 2012) and Learning by Collaborative Design (LCD) (SeitamaaHakkarainen et al., 2001; 2010). Both approaches share several similarities with other inquiry-based pedagogies, but in particular they focus on object-oriented learning, i.e. learning activities organized around the systematic and deliberate pursuit of knowledge-creation through shared "objects" (see Hakkarainen et al., 2004; Paavola et al., 2004). The main distinction between the approaches is that within LCD students create knowledge through constructing design artifacts, whereas in the DOP the emphasis is more on working with knowledge that is embedded in or bound to cultural artifacts or natural objects. 
The DOP (Liljeström et al., 2014; Vartiainen et al., 2012) emphasizes participatory perspectives on learning, and situates learning in out-of-school environments. The DOP framework consists of four main phases: articulation of the phenomenon, designing of the learning object, data collection of the learning object, and construction of the learning object. Typically the process begins at school and then extends to a natural or cultural environment (such as a forest or museum), and to network communities. The learning process is anchored on students' ideas, thoughts, conceptions, and interpretations about the shared design task, and participation in an expert community is driven by the students' own interests and research questions. Students work together in teams in pursuit of advancing their own understanding to be shared with the extended community. Moreover, the DOP employs the notion of self-organizing systems of participatory cultures by underlining that the process is not scripted in detail in advance, but has to be negotiated and actively designed by the learners themselves.

Similarly, the LCD approach (Seitamaa-Hakkarainen et al., 2001; 2010) emphasizes the open-endedness of the design learning process, as well as distributed expertise and collaboration in all the phases of the process. Design problems are complex and multidisciplinary in nature, and competence in design results largely from interaction and collaboration with other individuals. Drawing on over twenty years of educational research, the learning sciences have consistently proved that successful collaboration supports learning in many ways, for example, by fostering deep understanding (see e.g. Sawyer, 2006). The experiences of collaborative designing in educational settings appear to promote both participants' creativity and their practices of collective elaboration of design ideas (Fisher et al., 2005) as well as the implementation of these ideas in the actual design of artifacts. Furthermore, the LCD underlines the use of expert tools and practices already in elementary school, since expert knowledge is adapted to its purpose, and facilitates flexible problemsolving (Kangas et al. 2013a).

The DOP framework focuses particularly on knowledge-creation through natural or cultural artifacts in extended learning environments, the LCD is a more general approach to design learning especially applicable to technology education. In the next section, the background and elements of the LCD approach are described.

\section{Learning by Collaborative Design}

The Learning by Collaborative Design model (LCD) has its theoretical foundations in the pedagogical approaches of knowledge building (e.g. Bereiter \& Scardamalia, 2003; Scardamalia \& Bereiter, 2006) and progressive inquiry (e.g. Hakkarainen, 2009). In addition to discussing and sharing their opinions of the issues and themes under study, students engage in crystallizing, externalizing, sharing, and developing 
knowledge artifacts, such as sketches or prototypes, which embody their ideas (Scardamalia \& Bereiter, 2006). Creating new knowledge is seen to be a process embedded in the practices enacted, and knowledge is treated as something that can be shared and jointly developed (Hakkarainen, 2009). Knowledge is dealt through the design mode where the focal concern is the usefulness, adequacy, improvability, and developmental potential of all ideas (Bereiter \& Scardamalia, 2003). The LCD approach has been developed for over ten years, both in the higher education context (e.g. Lahti \& Seitamaa-Hakkarainen, 2004) as well as in elementary schools (e.g. Kangas et al., 2013b; Seitamaa-Hakkarainen et al., 2010; Viilo et al., 2011).

The visual LCD model depicts designing as a spiral and cyclical process that is approached iteratively through successive sequences (Figure 1). The model consists of the following phases: (1) creating the design context, (2) defining the design task and related design constraints, (3) creating conceptual and visual (physical) design ideas, (4) evaluating design ideas and constraints, (5) connecting to expert communities and collecting data, (6) experimenting and testing design ideas by sketching, modeling and prototyping, (7) evaluating functions of prototypes and (8) elaborating design ideas and redesigning. However, the phases of the LCD model are not a prescription of rigidly specified design stages; rather, they describe the intertwined facets of the complex and iterative design process. The participants (students, teachers, and domain experts) share their expertise in creating a meaningful and authentic design context and task for analyzing design constraints and collecting knowledge, as well as providing feedback, in order to develop a shared design object.

insert Fig. 1.about here

Fig. 1. The model of Learning by Collaborative Design

(adapted from Seitamaa-Hakkarainen et al., 2010)

While the knowledge building pedagogy highlights conceptual aspects of inquiry (e.g. students' own theories), the LCD approach additionally underlines the role of tools, instruments, prototypes, and other physically embodied aspects of inquiry as essential parts of the process (see Hakkarainen, 2009); the interaction through and around these design elements is primary. Designing involves the creation and use of various forms of 2D and 3D representations, such as sketches, drawings, mind maps, material collages, mock-ups, and prototypes. Through visualization and materialization, design ideas become visible for joint evaluation and development, therefore, externalization of ideas plays a crucial role in collaborative designing. From the beginning to the end, the design process is mediated by the shared artefacts being designed. Thus, constant cycles of idea generation, and testing of design ideas by visual modelling or prototyping, characterize the process. The participants transform conceptual ideas into material forms in a way that, in turn, elicit further elaboration of ideas. 
The following two sections of this chapter concentrate on the focal elements of the LCD approach. First, the role of design tasks and constraints within technology education is examined, and second, the mediated and embodied nature of design practices is studied.

\section{The Role of Design Tasks and Design Constraints}

The LCD approach emphasizes an authentic design task situated in a meaningful context as the foundation of the whole design learning process. Furthermore, the model highlights design constraints as essential characteristics of the process. Setting up a design task for the students is a constant quest for balance between the openness and constraints of the task. According to Sawyer (2012) too much openness or a lack of constraints may lead to traditional ways of making, whereas tasks that have constraints in balance prevent students from following familiar patterns and lead them to more advanced conceptions.

An authentic task refers to a problem that is both coherent and personally meaningful, as well as purposeful within a social framework (Hennessy \& Murphy, 1999). Within the framework of designing, problems have a special nature and a particular structure. Design problems are ill-defined and ill-structured (Goel \& Pirolli, 1992), that is, they are complex, open-ended, and dynamic; the process of solving the problem is parallel with the understanding of its nature (Dorst \& Cross, 2001; Lawson, 2006). Creative designing simultaneously develops and refines both the design problem at hand, as well as ideas for its solution, with constant iteration of analysis, synthesis, and evaluation processes (Dorst, 2006; Dorst \& Cross, 2001).

In principle, the number of possible solutions to design problems is unlimited, which can be overwhelming for young students learning design. However, design constraints determine and limit the amount of solutions (Lawson, 2006). Such constraints have a central role in the design process; through them a designer is able to construct a rationale for design decisions (Goel \& Pirolli, 1992; Goel, 1995; Seitamaa-Hakkarainen \& Hakkarainen, 2000). Lawson (2006) divides the design constraints into two main types, those that are linked with some external factor not under the designer's control (e.g. user needs), or those that are internal to the system or object being designed (e.g. safety regulations). External constraints are generated through the needs of participants in the design process; the requirements of the physical environment of the product being designed; or in terms of available resources, among other factors. They are more rigid than internal constraints, and can sometimes determine the whole form of the process. On the other hand, external constraints can be inspirational and compose the very essence of the special, possibly unique, context for designing. Internal constraints form the basis of the problem 
solving process, are flexible, and have only an abstract connection to the designed object.

As described above, the LCD model underlines collaboration and distributed expertise in all the phases of the design learning process, including the definition of the design task and the constraints. In schools generally, and in technology education particularly, design projects can address several themes from cultural phenomena to interdisciplinary topics. The meaning of the process is constructed by the teacher, on one hand, who embeds different goals to the design tasks and anchors it to students' previous knowledge. On the other hand, the reason for designing is formulated by the students themselves through the process of framing the design task, generating design ideas, and constructing the problem and solution simultaneously (Laamanen \& Seitamaa-Hakkarainen, 2014). When students are actively involved in formulating the design task and the related constraints, they are better able to deal with the ambiguity of the design process, and they become more capable of seeing structure in the complex and open-ended design task. Further, they are better able to focus their attention on the relevant aspects of the design problem space, to move beyond their familiar patterns, and to carry out multidimensional reflections of design ideas (Kangas et al., 2013a, 2013b).

\section{Mediated and Embodied Design Practices}

The design context, task, and constraints described above form the basis of the design process, but they are also further defined through design practices implemented - in the course of design ideation as well as iterative experimentation, evaluation, and elaboration of ideas (see Figure 1). In designing, and in technology education, the practices enacted are socially and materially mediated, as well as embodied in nature. Learning in design and technology takes place through several levels of interaction: verbal and non-verbal communication with others; interaction with tools and machines; thinking and communicating through sketches, pictures, drawings, and instructions; and through materials, products, aesthetic and emotional experiences (Illum \& Johansson, 2012; Johansson, 2006).

In design ideation the emphasis is on seeing beyond the obvious and developing personal constraints on the design task; it is the start of the generating-transforming process in which a designer uses knowledge, skills, materials, and tools in order to create something new or change a situation. Designers usually employ sketches as the first step of the process, for externalizing and visualizing ideas at an individual level (Goel, 1995). Sketching has a crucial role in generating, developing, and com- 
municating ideas; it is both a powerful form of thinking and the fundamental language of designing (Hope, 2000; MacDonald, Gustafson, \& Gentilini, 2007; Welch et al., 2000). Designing is also material-centric and object-oriented; engagement with and manipulation of physical materials is often an intrinsic part of the design process (Ramduny-Ellis et al., 2010). Designers build various kinds of models to explore their ideas in 3D form, from sketch models to appearance models and functional prototypes (Pei et al., 2010). Material properties affect both the process and the outcomes of design activity, constraining and inspiring the work of a designer (Ramduny-Ellis et al., 2010).

The various design representations are focal in the work of professional designers, however, the function and significance of these representations is not apparent for school children learning design (Hope, 2000; MacDonald, Gustafson, \& Gentilini, 2007; Welch, 1998; 2000). The formal design representations can become prioritized at the expense of participation and learning when the purpose and advantages of using them as design tools is not understood (Murphy \& Hennessy, 2001). Therefore, students should be more explicitly taught how to use varied tools and techniques to facilitate the generation, not just the execution, of ideas (MacDonald, Gustafson, \& Gentilini, 2007). In order to achieve this, students should be involved in several projects in which they can practice externalizing with different types of mediums. Drawing is often considered a most common tool that expert designers use, however, students usually experience drawing as very challenging. If possible, young students tend to move immediately to three-dimensional modeling (Welch, 1998), and these material, as well as verbal, methods may similarly support ideation.

Usually cheap and easy-to-manipulate materials (e.g. cardboard, masking tape, wire) are used for modeling, however, rapid prototyping tools, such as 3D printers, laser cutters, virtual modeling tools, and sue of CAD programs, provide new possibilities for design and technology education. These so-called maker technologies allow elements of a design to be easily changed and manipulated, enabling multiple iterations of testing and making models, and encouraging students to take risks in exploring novel solutions. Mistakes and failures are seen as natural parts of the process, providing opportunities for reflection and further advancement of learning (Blikstein, 2013). According to Campbell and Jane (2012) understanding various representation methods, recognizing how they are used to construct explanations, and negotiating the meaning of different representations are crucial to learning in technology education.

Besides the social and material aspects of designing, recent research has emphasized the embodied dimensions of design work, i.e. how the body is actively involved in designers' thinking and communication processes (e.g. Keller \& Keller, 1996; Poulsen \& Thøgersen, 2011). Competence in design develops through several connected levels - social, material, and embodied - of thinking, interacting, and mean- 
ing making. Authentic design tasks are challenging and require distribution of expertise in various ways: between humans; between humans, tools, materials, and the surrounding space; and between mind and body. Further, designing requires the generation and use of various kinds of knowledge in order to know, on one hand, how to do design, and, on the other hand, how to generate the new knowledge that such doing requires (see Vincenti, 1990). In technology education, the co-evolution of conceptual, material, practice-related, and physically embodied artifacts and activities is essential for the advancement of students' design ideas (Kangas et al., 2013a, 2013b). This, however, requires careful facilitation; students need support at all levels of interaction and in moving between levels. They need to learn, for example, how to collaborate constructively, how to use tools and materials, or how to produce and use design representations for generating, developing, storing, and communicating ideas.

\section{Conclusions and Future Directions}

Design learning aims to develop one's ability to see beyond the obvious, to experiment with new ideas by sketching and prototyping, to make leaps of imagination as well as to systematically analyze, generalize, and synthesize observations. Openended design projects challenge traditional ways of learning by, for example, disrupting the notion of "right" answers and the ideal of measurable achievement (Kafai et al., 2014). They provide novel possibilities for learning and knowledgecreation, as from their very premise, they aim to create something new. Further, since the objects and effects of design are daily apparent all around us, engaging in and comprehending design processes provides a means of developing a deep understanding of the less tangible issues affecting us humans and the world we inhabit. Through designing, students can be socialized to creative practices of working with knowledge, which is seen as a fundamental future competence.

However, teaching designing to young students requires a great deal from the teacher: accepting uncertainty, maintaining motivation and engagement, and fitting the whole project into restricted time, space, and material resources. Creative processes have an inherent power of motivation, but the process needs to be encouraged by, for example, enabling choice and self-direction (Campbell \& Jane, 2012). As a starting point, the design learning process requires an open-ended design task that is both authentic and meaningful, and that has constraints in balance. The task should also provide ways of generating meaning for the process in order to pursue ideation towards wider contexts of learning (Laamanen \& Seitamaa-Hakkarainen, 2014). In addition, the design process should include various tools and techniques for generating ideas, so that students can learn to understand the dynamics of design ideation. Students should be guided to constantly move between thinking and doing 
activities, in order for knowledge-creation to take place on social, material, and embodied levels of interaction.

In order to answer these challenges and to find new pathways for learning, educators and researchers in the field of design and technology education have started to examine the ideas and implementation of the maker movement (e.g. Blikstein, 2013; Kafai et al., 2014). Applied to educational contexts, the maker movement represents a form of learning by doing, which might appear to echo the earlier formal apprenticeship model of learning, but instead emphasizes informal, networked, peer-led, and shared learning activities in a community of practice. It underlines experimentation, innovation, and the testing of theory through practical, self-directed tasks and production of tangible artifacts, and is seen as having the potential to contribute to a more participatory approach to learning. From the perspective of knowledgecreation, maker activities contribute to the development of students' sense of identity and agency, which enables them to see themselves as capable of improving ideas and creating knowledge. The maker movement includes not only the process of creating artifacts, but also the social and learning cultures surrounding their construction. These communities are both physical and virtual, and according to Thomas and Brown (2011), particularly online collectives represent a new culture of learning, where learning emerges from the environment and grows along with it. This kind of learning is suited for our world of constant change, because it comprises two important elements: a massive information network providing almost unlimited access and resources to learn about anything and a constrained and structured environment that allows for unlimited agency to build and experiment with anything within the boundaries of that environment.

There is some research available on designing in the field of technology education, providing insights into, for example, various aspects of teaching and learning design (for review, see Williams, 2016). The research suggests, for example, that designing supports students' engagement in authentic practice and provides a route to deep learning. However, to a much lesser extent, research has systemically addressed the question of what is actually learned through designing, what kind of knowledge the students generate, and how this is related to a given curriculum. This challenge is partly connected to the desired learning gains; how is it possible to define what counts as success or evidence of the development of complex cultural practices that may take several years to become fully articulated? Nevertheless, more research is needed that provides evidence that design activities will lead to measurable advancement in depth of understanding of the design inquiry process, mastery of associated methods and practices, intellectual engagement as well as an enhanced sense of being able to contribute to collective knowledge creation efforts. 


\section{References}

Bereiter, C. \& Scardamalia, M. (2003). Learning to work creatively with knowledge. In E. de Corte, L. Verschaffel, N. Entwistle, J. van Merriënboer (Eds.), Powerful learning environments. Unravelling basic components and dimensions (pp. 55-68). Oxford, UK: Pergamon/Elsevier Science.

Blikstein, P. (2013). Digital fabrication and making in education: The democratization of invention. In J. Walter-Herrmann, \& C. Büching (Eds.), FabLab. Of machines, makers, and inventors (pp. 203-222). Bielefeld, Germany: Transcript.

Campbell, C. \& Jane, B. (2012). Motivating children to learn: the role of technology education. International Journal of Technology and Design Education, 22(1), 1-11.

Dahlin, L. K., Voll, L. O., \& Svorkmo, A. (2013). Technology and design as part of a public school from 1st to 10th grade. In J. B. Reitan, P. Lloyd, E. Bohemia, L. M. Nielsen, I. Digranes, \& E. Lutnaes (Eds.), Design learning for tomorrow. Design education from kindergarten to PhD. proceedings from the $2^{\text {nd }}$ International Conference for Design Education Researchers, Vol 4 (pp. 1938-1950). Oslo, Norway: ABM-media.

de Vries, M. (2009). The developing field of technology education: An introduction. In M. de Vries \& A. Jones (Eds.), International handbook of research and development in technology education (pp. 1-9). Rotterdam: Sense.

Dorst, K. (2006). Design problems and design paradoxes. Design Issues, 22(3), 4-17.

Dorst, K. \& Cross, N. (2001). Creativity in the design process: Co-evolution of problem-solution. Design Studies, 22(5), 425-437.

Fischer, G., Giaccardi, E., Eden, H., Sugimoto, M., \& Ye, Y. (2005). Beyond binary choices: Integrating individual and social creativity. International Journal of Human-Computer Studies, 63(4), 482-512.

Fortus, D., Dershimer, R.C., Krajcik, J., Marx, R.W., \& Mamlok-Naaman, R. (2004). Designbased science and student learning. Journal of Research in Science Teaching, 41(10), 10811110.

Goel, V. (1995). Sketches of thought. Cambridge, MA: MIT Press.

Goel, V. \& Pirolli, P. (1992). The structure of design problem spaces. Cognitive Science, 16(3), 395-429.

Hakkarainen, K. (2009). Three generations of technology-enhanced learning. British Journal of Educational Technology, 40(5), 879-888.

Hakkarainen, K., Palonen, T., Paavola, S., \& Lehtinen, E. (2004). Communities of networked expertise: Professional and educational perspectives. Amsterdam: Elsevier.

Harel, I. (1991). Children designers. New York: Ablex.

Hennessy, S. \& Murphy, P. (1999). The potential for collaborative problem solving in design and technology. International Journal of Technology and Design Education, 9(1), 1-36.

Hope, G. (2000). Beyond draw one and make it. The Journal of Technology and Design Education, $6(3), 197-201$.

Illum, B., \& Johansson, M. (2012). Transforming physical materials into artefacts - learning in the school's practice of sloyd. Techne Series A, 19(1), 2-16.

International Technology Education Association (ITEA) (2007). Standards for technological literacy: Content for the study of technology (3rd ed). Retrieved from http://www.iteaconnect.org/TAA/PDFs/xstnd.pdf. Accessed 22 April 2013.

Johansson, M. (2006). The work in the classroom of sloyd. Journal of Research in Teacher Education, 13(2-3), 152-171.

Kafai, Y.B. (2006). Constructionism. In R. K. Sawyer (Ed.), The Cambridge handbook of the learning sciences (pp. 35-46). New York: Cambridge University Press.

Kafai Y.B., Fields, D.A., \& Searle, K.A. (2014). Electronic textiles as disruptive designs: Supporting and challenging maker activities in schools. Harvard Educational Review, 84(4), 532-556. 
Kangas, K., Seitamaa-Hakkarainen, P., \& Hakkarainen, K. (2013a). Figuring the world of designing: Expert participation in elementary classroom. International Journal of Technology and Design Education, 23(2), 425-442.

Kangas, K., Seitamaa-Hakkarainen, P., \& Hakkarainen, K. (2013b). Design thinking in elementary students' collaborative lamp designing process. Design and Technology Education: an International Journal, 18(1), 30-43.

Keller, C. \& Keller, J.D. (1996). Cognition and tool use. The blacksmith at work. New York: Cambridge University Press.

Kelley T. R., \& Sung, E. (2016). Sketching by design: teaching sketching to young learners. International Journal of Technology and Design Education, OnLine First.

Kolodner, J.L., Camp, P.J., Crismond, D., Fasse, B., Gray, J., Holbrook, J., . . Ryan, M. (2003). Problem-based learning meets case-based reasoning in the middleschool science classroom: Putting Learning by Design ${ }^{\mathrm{TM}}$ into practice. Journal of the Learning Sciences, 12(4), 495-547.

Krajick, J. \& Merritt, J. (2012). Engaging Students in Scientific Practices: What does constructing and revising models look like in the science classroom? Science and Children 49(7), 10-13.

Laamanen, T.K. \& Seitamaa-Hakkarainen, P. (2014). Constraining the open-ended design task by interpreting sources of inspiration. Art, Design and Communication in Higher Education, $13(2), 135-156$

Lahti, H., Seitamaa-Hakkarainen, P. \& Hakkarainen, K. (2004). Collaboration patterns in computer-supported collaborative designing. Design Studies, (25)4, 351-371.

Lawson, B. (2006). How designers think: The design process demystified (4th ed). Oxford: Architectural Press.

Liljeström, A., Enkenberg, J., \& Pöllänen, S. (2014). The case of Design-oriented pedagogy: What students' digital video stories say about emerging learning ecosystems. Education and Information Technologies, 19(3), 583-601.

MacDonald, D., Gustafson, B. J., \& Gentilini, S. (2007). Enhancing children's drawing in design technology planning and making. Research in Science \& Technological Education 25(1), 59-75.

Murphy, P. \& Hennessy, S. (2001). Realising the potential - and lost opportunities - for peer collaboration in a D\&T setting. International Journal of Technology and Design Education, 11(3), 203-237.

Paavola, S., Lipponen, L., \& Hakkarainen, K. (2004). Modeling innovative knowledge communities: A knowledge-creation approach to learning. Review of Educational Research, 74, $557-$ 576.

Papert, S. (1991). Situating constructionism. In S. Papert \& I. Harel (Eds.), Constructionism. Cambridge, MA: MIT Press.

Pei, E., Campbell, I.R., \& Evans M.A. (2010). Development of a tool for building shared representations among industrial designers and engineering designers. CoDesign, 6(3), 139-166.

Poulsen, S.B. \& Thøgersen, U. (2011). Embodied design thinking: A phenomenological perspective. CoDesign, 7(1), 29-44.

Ramduny-Ellis, D., Dix, A., Evans, M., Hare, J., \& Gill, S. (2010). Physicality in design: An exploration. Design Journal, 13(1), 48-76.

Sawyer, K.R. (2006). Introduction: The new science of learning. In K. R. Sawyer (Ed.), The Cambridge handbook of the learning sciences (pp. 1-16). New York: Cambridge University Press.

Sawyer, K. (2012). Learning how to create: Toward a learning sciences of Art and Design. In J. van Aalst, K. Thompson, M.J. Jacobson, \& P. Reimann (Eds.), The future of learning: Proceedings of the 10th International Conference of the Learning Sciences (ICLS 2012), Vol. 1, full papers (p. 33-36). Sydney, NSW, Australia: International Society of the Learning Sciences.

Scardamalia, M. \& Bereiter, C. (2003). Knowledge building. In Encyclopedia of education (2nd ed) (pp. 1370-1373). New York: Macmillan Reference.

Seitamaa-Hakkarainen, P. \& Hakkarainen, K. (2000). Visualization and sketching in the design process. The Design Journal, 3(1), 3-14. 
Seitamaa-Hakkarainen, P., Raunio, A-M., Muukkonen, H., \& Hakkarainen, K. (2001). Computer support for collaborative designing. International Journal of Technology and Design Education, 11(2), 181-202.

Seitamaa-Hakkarainen, P., Viilo, M., \& Hakkarainen, K. (2010). Learning by collaborative designing: Technology-enhanced knowledge practices. International Journal of Technology and Design Education, 20(2), 109-136.

Thomas, D. \& Brown J.S. (2011). A new culture of learning: Cultivating the imagination for a world of constant change. Lexington, KY: CreateSpace.

Vartiainen, H., Liljeström, A., \& Enkenberg, J. (2012). Design-oriented pedagogy for technologyenhanced learning to cross over the borders between formal and informal environments. Journal of Universal Computer Science, 18(15), 2097-2119.

Viilo, M., Seitamaa-Hakkarainen, P., \& Hakkarainen, K. (2011). Supporting the technology-enhanced collaborative inquiry and design project: A teacher's reflections on practices. Teachers and Teaching: Theory and Practice, 17(1), 51-72.

Vincenti, W.G. (1990). What engineers know and how they know it. Analytical studies from aeronautical history. Baltimore, MD: The Johns Hopkins University Press.

Welch, M. (1998). Students' use of three-dimensional modelling while designing and making a solution to a technological problem. International Journal of Technology and Design Education, 8(3), 241-260.

Welch, M., Barlex, D., \& Lim, H.S. (2000). Sketching: Friend or foe to the novice designer? International Journal of Technology and Design Education, 10(2), 125-148.

Williams, P.J. (2016). Research in technology education: Looking back to move forward... again. International Journal of Technology and Design Education, 26(2), 149-157.

\section{Cross-references}

Blikstein P. Making (maker movement).

Cunningham C. Primary education specific issues.

de Vries M. History of Technology Education internationally.

Esjeholm B, Bungum B. Design-research interaction in classroom activities

Fox-Turnbull W. Classroom interaction in Technology Education

Hill A. Authentic learning

Pitt J. Science-technology relations

Williams J. History of research for Technology Education.

Keywords Design learning, Collaborative designing, Design problems, Design constraints, Design practices 